10th International Symposium on Process Systems Engineering - PSE2009

Rita Maria de Brito Alves, Claudio Augusto Oller do Nascimento and Evaristo

Chalbaud Biscaia Jr. (Editors)

(C) 2009 Elsevier B.V. All rights reserved.

\title{
A Dynamical Model for the fermentative production of fructooligosaccharides
}

O. Rocha ${ }^{\mathrm{a}, \mathrm{b}}$, C. Nobre ${ }^{\mathrm{a}}$, A. Dominguez ${ }^{\mathrm{a}}$, D. Torres ${ }^{\mathrm{a}, \mathrm{b}}$, N. Faria ${ }^{\mathrm{b}}$, L. Rodrigues ${ }^{\mathrm{a}, \mathrm{b}}$, J.A. Teixeira ${ }^{a}$, E.C. Ferreira ${ }^{a}$ and I. Rocha ${ }^{a, b}$

${ }^{a}$ IBB - Institute for Biotechnology and Bioengineering, Centre of Biological

Engineering, Universidade do Minho, Campus de Gualtar, 4710-057 Braga, PORTUGAL

${ }^{b}$ Biotempo, Lda., Avepark - Zona Industrial da Gandra, Apartado 4152, 4806 - 909,

Caldas das Taipas, Braga, Portugal

\begin{abstract}
In this paper a detailed mathematical model is presented for the fermentative production of fructo-oligosaccharides with Aspergillus sp. The model accounts for hydrolysis and transfructolization reactions, as well as biomass formation and it contains 27 parameters that were determined from experimental data using a System Biology toolbox with the Simulated Annealing method for curve fitting. Several additional experiments were performed in bioreactors where the time variation of 7 state variables (Sucrose, Glucose, Fructose, 1-Kestose, Nystose, 1-fructosyl nystose and Biomass) was measured.

Experimental data were compared with results from simulations using the estimated parameters and it was verified that the model can predict the FOS production profile. The good agreement between simulated and experimental data was verified by calculating the relative percentage deviation modulus, which was lower than $10 \%$ for all cases except one. The derived and validated model can be used for process optimization, for example for indicating which fed-batch strategy could be used to improve the production of FOS while minimizing glucose concentration.
\end{abstract}

Keywords: Modelling, Simulation, Fructooligosaccharides.

\section{Introduction}

Within Industrial Biotechnology, a very promising application is the production of ingredients for functional foods, since the market for those products has been growing at very interesting rates [9]. In recent years some prebiotics have been described as beneficial food ingredients because of their proprieties of modifying the intestinal microbiota, favoring the growth of some beneficial bacteria $[1 ; 2 ; 10 ; 11]$. Fructooligosaccharides (FOS) have become one of the most important prebiotic products with healthy properties, being possible to find them, usually in trace amounts, as natural components in fruits, vegetables and honey [8;11]. Although industrially these products are mainly extracted from those natural sources, they can be also produced from sucrose by the action of $\beta$ - fructofuranosidase [FFase; EC 3.2.1.261] obtained from some organisms. Various fungi such as Aureobasidum sp., Aureobasidum pullulans, Aspergillus niger, Aspergillus japonicas, Aspergillus oryzae and Scopulariopsis brevicaulis $[3 ; 5 ; 6 ; 8 ; 12 ; 13 ; 15]$ produce those oligosaccharides that are mainly composed of 1-Kestose, Nystose, and Fructosylfuranosyl nystose in which 1-3 fructose units are bound at the $\beta-2,1$ position of sucrose [16]. 
However, besides the fructosyltransferase activity, $\beta$-fructofuranosidase also exhibits hydrolytic activity $[4 ; 5 ; 7 ; 12]$, which can dominate the process depending on a combination of factors including the sucrose concentration. This fact will ultimately lead to lower production yields and to a contamination of the final product with the monosaccharides glucose and fructose. Additionally, in a fermentative process for the production of FOS, substrate consumption for biomass growth has also to be considered, increasing even further the complexity of the process and motivating the application of mathematical modelling approaches such that non-obvious operation conditions can subsequently be found that maximize the productivity of FOS and minimize the accumulation of monosaccharides.

\section{Mathematical Model}

The main aim of this work was to formulate a general model that characterizes the main reactions representing the fermentative FOS production process. It is based on the empirical equations of enzymatic production of fructooligosaccharides from sucrose. The model contemplates both hydrolysis and transfructosylation kinetic equations representing $\beta$ - fructofuranosidase activity and growth rate equations for the microorganism. The enzymatic reactions were divided in two main categories: the hydrolysis reactions, representing FOS and sucrose degradation, and the transfructosylation reactions that describe FOS synthesis. In the formulation of the model only three different FOS were considered: 1-Kestose, Nystose, 1- fructofuranosyl nystose. A prior analysis of fermentation samples by HPLC indicated only the presence of these oligosaccharides.

\subsection{Hydrolysis reactions}

The hydrolysis of saccharose and FOS by $\beta$ - fructofuranosidase is described by equations 2 to 5 . It is considered that all the di- and oligo-saccharides can be hydrolysed by the action of the enzyme.

$$
\begin{aligned}
& G F \stackrel{r 1}{\longrightarrow} k_{1} \cdot G+k_{2} \cdot F \\
& G F_{2} \stackrel{r 2}{\longrightarrow} k_{3} \cdot G F+k_{4} \cdot F \\
& G F_{3} \stackrel{r 3}{\longrightarrow} k_{5} \cdot G F_{2}+k_{6} \cdot F \\
& G F_{4} \stackrel{r 4}{\longrightarrow} k_{7} \cdot G F_{3}+k_{8} \cdot F
\end{aligned}
$$

Duan and co-authors [4] proposed a Michaelis-Menten equation with substrate inhibition to represent nystose hydrolysis. In our model, this phenomenon was considered to occur also during the hydrolysis of 1-kestose and 1-Fructosylfuranosyl nystose. The FOS hydrolysis kinetic equation is then given by:

$$
r_{i}=\frac{V m h_{G F i} \times G F_{i}}{G F_{i}\left(1+\frac{G F_{i}}{K i h_{G F i}}\right)+K m h_{G F i}}
$$

with $i=2,3,4$, where $r_{i}$ is the $\mathrm{i}^{\text {th }}$ fructooligosaccharide hydrolysis rate $\left(\mathrm{g} \mathrm{L}^{-1} \mathrm{~h}^{-1}\right)$, $V m h_{\mathrm{GFi}}$ is the maximum hydrolysis rate $\left(\mathrm{g} \mathrm{L}^{-1} \mathrm{~h}^{-1}\right), G F_{\mathrm{i}}$ is the concentration $\left(\mathrm{g} \mathrm{L}^{-1}\right)$ of nystose, 1-kestose or 1-Fructosylfuranosyl nystose, $\mathrm{Kih}_{\mathrm{GFi}}$ is the substrate inhibition constant $\left(\mathrm{g} \mathrm{L}^{-1}\right)$, and $K m h_{\mathrm{GFi}}$ is the Michaelis-Menten constant $\left(\mathrm{g} \mathrm{L}^{-1}\right)$ for $G F_{\mathrm{i}}$.

For sucrose hydrolysis, a Michaelis-Menten equation was used, given by: 
$r_{1}=\frac{V m h_{G F} \times G F}{K m h_{G F}+G F}$

where $V m h_{\mathrm{GF}}$ is the maximum hydrolysis rate $\left(\mathrm{g} \mathrm{L}^{-1} \mathrm{~h}^{-1}\right), G F$ is the sucrose concentration $\left(\mathrm{g} \mathrm{L}^{-1}\right)$ and $\mathrm{Kmh}_{\mathrm{GF}}$ is the Michaelis-Menten constant for sucrose $\left(\mathrm{g} \mathrm{L}^{-1}\right)$.

\subsection{Transfructosylation reactions}

The formation of oligosaccharides can occur by a transition of a fructosyl residue from one molecule to another like it was described by Duan and co-authors [4]:

$2 G F \stackrel{r 5}{\longrightarrow} k_{9} . G F_{2}+k_{10} \cdot G$

$2 G F_{2} \stackrel{r 6}{\longrightarrow} k_{11} \cdot G F_{3}+k_{12} \cdot G F$

$2 G F_{3} \stackrel{r 7}{\longrightarrow} k_{13} \cdot G F_{4}+k_{14} \cdot G F_{2}$

In sucrose transfructosylation, represented by equation 7, a Michaelis-Menten equation with substrate inhibition and competitive glucose inhibition was used:

$r_{5}=\frac{V m T_{G F} \times G F}{G F\left(1+\frac{G F}{K s t s}\right)+K m s t\left(1+\frac{G}{K g s t}\right)}$

where $r_{5}$ is the sucrose transfructosylation rate $\left(\mathrm{g} \mathrm{L}^{-1} \mathrm{~h}^{-1}\right), V m T_{G F}$ is the maximum transfructosylation rate $\left(\mathrm{g} \mathrm{L}^{-1} \mathrm{~h}^{-1}\right), G F$ is the sucrose concentration $\left(\mathrm{g} \mathrm{L}^{-1}\right)$, Ksts is the substrate inhibition constant $\left(\mathrm{g} \mathrm{L}^{-1}\right)$ for sucrose as a substrate, Kgst is the competitive inhibition constant $\left(\mathrm{g} \mathrm{L}^{-1}\right)$ for glucose and Kmst is the Michaelis-Menten constant $\left(\mathrm{g} \mathrm{L}^{-1}\right)$ for sucrose.

Equations 8 and 9 represent the Nystose and 1-kestose transfructosylation reactions. A competitive glucose inhibition term was also included in the Michaelis-Menten equation, since Duan [4] reported this phenomenon for these two fructooligosaccharides. Equation 11 represents the fructooligosaccharides transfructosylation reaction rates:

$$
r_{j}=\frac{V m T_{G F i} * G F_{i}}{G F_{i}+K m t_{G F i}\left(1+\frac{G}{K i t_{G F i}}\right)}
$$

with $\mathrm{i}=2,3 ; \mathrm{j}=6,7$; where $V m T_{G F i}$ is the maximum transfructosylating rate $\left(\mathrm{g} \mathrm{L}^{-1} \mathrm{~h}^{-1}\right)$, $G F_{i}$ is the FOS concentration $\left(\mathrm{g} \mathrm{L}^{-1}\right), K m t_{G F i}$ is the Michaelis-Menten constant $\left(\mathrm{g} \mathrm{L}^{-1}\right)$ for the $G F_{i}$ oligosaccharide and itt $_{G F i}$ is the competitive inhibition constant $\left(\mathrm{g} \mathrm{L}^{-1}\right)$.

\subsection{Growth reactions}

The formation of biomass can either occur from glucose or fructose consumption and can be described by:

$Y_{G} G \stackrel{r_{8}}{\longrightarrow} X$

$Y_{F} F \stackrel{r 9}{\longrightarrow} X$

Since substrate consumption for maintenance was considered to be significantly smaller, it was neglected. The proposed Monod equations are given as follows:

$$
r_{j}=\frac{\mu_{j, \max } \cdot S_{j} \cdot X}{S_{j}+K S_{j}}
$$


$\mathrm{r}_{j}=8,9$; where $r_{j}$ is the growth rate of the microorganism $\left(\mathrm{g} \mathrm{L}^{-1} \mathrm{~h}^{-1}\right), \mu_{j, \text { max }}$ is the maximum specific growth rate $\left(\mathrm{h}^{-1}\right)$ on glucose or fructose, $S_{j}$ is the glucose or fructose concentration $\left(\mathrm{g} \mathrm{L}^{-1}\right), X$ is the biomass concentration $\left(\mathrm{g} \mathrm{L}^{-1}\right)$ and $K S_{j}$ is the affinity constant for the substrate $\left(\mathrm{g} \mathrm{L}^{-1}\right)$. The $Y_{G}$ and $Y_{F}$ in equations 12 and 13 are the biomass yields when the glucose or fructose are used for biomass growth $\left(\mathrm{g} \mathrm{g}^{-1}\right)$.

2.4. Derivation of model equations

After establishing both the reaction scheme and the kinetic equations, a general dynamical model of the process accounting for mass transfer, biomass growth and enzymatic reactions was defined. In the formulation of this model 7 state variables have been considered: sucrose $(G F)$, Glucose $(G)$, Fructose $(F)$, 1-Kestose $\left(G F_{2}\right)$, Nystose $\left(G F_{3}\right), 1$-fructofuranosyl nystose $\left(G F_{4}\right)$ and Biomass $(X)$.

The time derivatives of the concentration of studied components for a fed-batch bioreactor are given as:

$$
\begin{aligned}
& \frac{d G F}{d t}=\left(-r_{1}+k_{3} \cdot r_{2}-r_{5}+\frac{k_{12}}{2} \cdot r_{6}\right)+\frac{F_{i n}}{V} G F_{i n}-D \cdot G F \\
& \frac{d G}{d t}=\left(k_{1} \cdot r_{1}+\frac{k_{10}}{2} \cdot r_{5}-Y_{G} \cdot r_{8}\right)-D \cdot G \\
& \frac{d F}{d t}=\left(k_{2} \cdot r_{1}+k_{4} \cdot r_{2}+k_{6} \cdot r_{3}+k_{8} \cdot r_{4}+Y_{F} \cdot r_{9}\right)-D \cdot F \\
& \frac{d G F_{2}}{d t}=\left(-r_{2}+k_{5} \cdot r_{3}+\frac{k_{9}}{2} \cdot r_{5}-r_{6}+\frac{k_{14}}{2} \cdot r_{7}\right)-D \cdot G F_{2} \\
& \frac{d G F_{3}}{d t}=\left(-r_{3}+k_{7} \cdot r_{4}+\frac{k_{11}}{2} \cdot r_{6}-r_{7}\right)-D \cdot G F_{3} \\
& \frac{d G F_{4}}{d t}=\left(-r_{4}+\frac{k_{13}}{2} \cdot r_{7}\right)-D \cdot G F_{4} \\
& \frac{d X}{d t}=\left(r_{8}+r_{9}\right)-D \cdot X
\end{aligned}
$$

where $F_{i n, s}$ is the volumetric flow rate of sucrose feeding solution $\left(\mathrm{L} \mathrm{h}^{-1}\right) ; G F_{\text {in }}$ is the sucrose concentration on the feeding $(\mathrm{g} \mathrm{L}) ; D$ is the quotient between the total feed rate $\left(F_{i n, t o t a l}\right)$ and the $V$ is the total volume of liquid inside reactor $(\mathrm{L})$.

\section{Materials and Methods}

Two fermentations of Aspergillus sp. were performed in a $5 \mathrm{~L}$ fermentor (B. Braun Biotech International), model Micro-DCU 200 at a $\mathrm{pH}$ of 5 and $30^{\circ} \mathrm{C}$, with Czapek Dox Media of OXOID and an initial sucrose concentration of 200 grams per litre. During those fermentations, the time evolutions of the 7 state variables present in model were measured. The growth was monitored by dry cell weight, where three $10 \mathrm{~mL}$ samples were filtered with a 0.45 micron filter and dried at $105^{\circ} \mathrm{C}$ for $20 \mathrm{~h}$. The supernatant was used to determine the carbohydrates concentration. They were analyzed in a JASCO HPLC instrument with a refractive index detector using a VARIAN MetaCarb 87P column. The column was maintained at $25^{\circ} \mathrm{C}$, and a mixture of water and acetonitrile was used as a mobile phase at $1 \mathrm{~mL} \mathrm{~min}^{-1}$. 
Afterwards, the collected data were used for the determination of unknown kinetic and yield coefficients with a Simulated Annealing method included in the System biology toolbox [14]. For the estimation of kinetic and yield coefficients only data from one experiment of each microorganism were used. This experiment was chosen randomly. Data from the remaining experiments were used to validate the model accuracy.

The fitting was performed by minimizing a total cost function that represents the adjustment between experimental and simulated data:

Total $\cos t=\sum_{i=1}^{n}\left(\frac{1}{N_{p}} \sum_{j=1}^{p}\left(\frac{\xi_{\text {sim }, i j}-\xi_{\text {exp }, i j}}{\bar{\xi}_{\text {exp }, i j}}\right)^{2}\right)$

where $\xi_{\text {sim }, i j}$ represents the simulated data and $\xi_{\text {exp }, i j}$ is the experimental data for every point $(p)$ for a given state variable $(n)$ and $N p$ is the total number of data points. The difference is divided by an average value $\bar{\xi}_{\text {exp }, i j}$ with the purpose of attributing the same importance to all state variables.

\section{Results and Discussion}

The first task was to find the values for the 27 unknown parameters already described in model equations. The parameters obtained using the system biology toolbox are shown in Table 1. The values obtained were compared with some kinetic parameters values from literature [4], for a $\beta$ - fructofuranosidase derived from an Aspergillus japonicus. Subsequently a simulation was carried out in System Biology toolbox using those parameters and the results were compared with the experimental data obtained from a second fermentation. The comparison between simulated and experimental data is shown in figure 1 . These results show that the proposed mathematical model can predict correctly the time profiles for the state variables.

\section{Conclusions}

In this paper we present a detailed mathematical model for the production of fructooligosaccharides with Aspergillus sp. To the best of our knowledge, although several models representing the enzymatic reactions have been published, this is the first model that represents the fermentative process, therefore accounting for biomass formation.

Experimental data were compared with results from simulations using the estimated parameters and it was verified that the models can predict the FOS production.

Once the model is derived and validated, it can now be used for process optimization, for example for indicating which fed-batch strategy could be used to improve the production of FOS while minimizing glucose concentration.

\section{References}

1 Angeliki Kapiki, Christos Costalos, Christina Oikonomidou, Antigoni Triantafyllidou, Erini Loukatou and Vassiliki Pertrohilou. (2006) The effect of a fructo-oligosaccharide supplemented formula on gut flora of preterm infants. Early Human Development.

2 Bielecka,M., Biedrzycka,E., Majkowska,A., Juskiewicz,J. and Wroblewska,M. (2002) Effect of nondigestible oligosaccharides on gut microecosystem in rats. Food Research International, 35, 139-144.

3 Cruz,R., Cruz,V.D., Belini,M.Z., Belote,J.G. and Vieira,C.R. (1998) Production of fructooligosaccharides by the mycelia of Aspergillus japonicus immobilized in calcium alginate. Bioresource Technology, 65, 139-143.

4 Duan,K.J., Chen,J.S. and Sheu,D.C. (1994) Kinetic studies and mathematical model for enzymatic production of fructooligosaccharides from sucrose. Enzyme and Microbial Technology, 16, 334-339. 
5 Fernandez,R.C., Maresma,B.G., Juarez,A. and Martinez,J. (2004) Production of fructooligosaccharides by beta-fructofuranosidase from Aspergillus sp 27H. Journal of Chemical Technology and Biotechnology, $79,268-272$

6 Hatakeyama,Y., Takeda,H., Ooi,T. and Kinoshita,S. (1996) Kinetic parameters of beta-fructofuranosidase from Scopulariopsis brevicaulis. Journal of Fermentation and Bioengineering, 81, 518-523.

7 Kim,M.H., In,M.J., Cha,H.J. and Yoo,Y.J. (1996) An empirical rate equation for the fructooligosaccharideproducing reaction catalyzed by beta-fructofuranosidase. Journal of Fermentation and Bioengineering, 82 , 458-463.

8 Lee,W.C., Chiang,C.J. and Tsai,P.Y. (1999) Kinetic modeling of fructo-oligosaccharide production catalyzed by immobilized beta-fructofuranosidase. Industrial \& Engineering Chemistry Research, 38, 2564-2570.

9 Menrad,K. (2003) Market and marketing of functional food in Europe. Journal of Food Engineering, 56, 181-188.

10 Michael,B. (2002) Relationship of prebiotics and food to intestinal microflora. European Journal of Nutrition, V41.

11 Mikkelsen,L.L., Jakobsen,M. and Jensen,B.B. (2003) Effects of dietary oligosaccharides on microbial diversity and fructo-oligosaccharide degrading bacteria in faeces of piglets post-weaning. Animal Feed Science and Technology, 109, 133-150.

12 Sangeetha,P.T., Ramesh,M.N. and Prapulla,S.G. (2004) Production of fructo-oligosaccharides by fructosyl transferase from Aspergillus oryzae CFR 202 and Aureobasidium pullulans CFR 77. Process Biochemistry, 39, 755-760.

13 Sangeetha,P.T., Ramesh,M.N. and Prapulla,S.G. (2005) Recent trends in the microbial production, analysis and application of Fructooligosaccharides. Trends in Food Science \& Technology, 16, 442-457.

14 Schmidt,H. and Jirstrand,M. (2006) Systems Biology Toolbox for MATLAB: a computational platform for research in systems biology. Bioinformatics, 22, 514-515.

15 Sheu,D.C., Duan,K.J., Cheng,C.Y., Bi,J.L. and Chen,J.Y. (2002) Continuous production of high-content fructooligosaccharides by a complex cell system. Biotechnology Progress, 18, 1282-1286.

16 Shin,H.T., Baig,S.Y., Lee,S.W., Suh,D.S., Kwon,S.T., Lim,Y.B. and Lee,J.H. (2004) Production of fructooligosaccharides from molasses by Aureobasidium pullulans cells. Bioresource Technology, 93, 59-62.
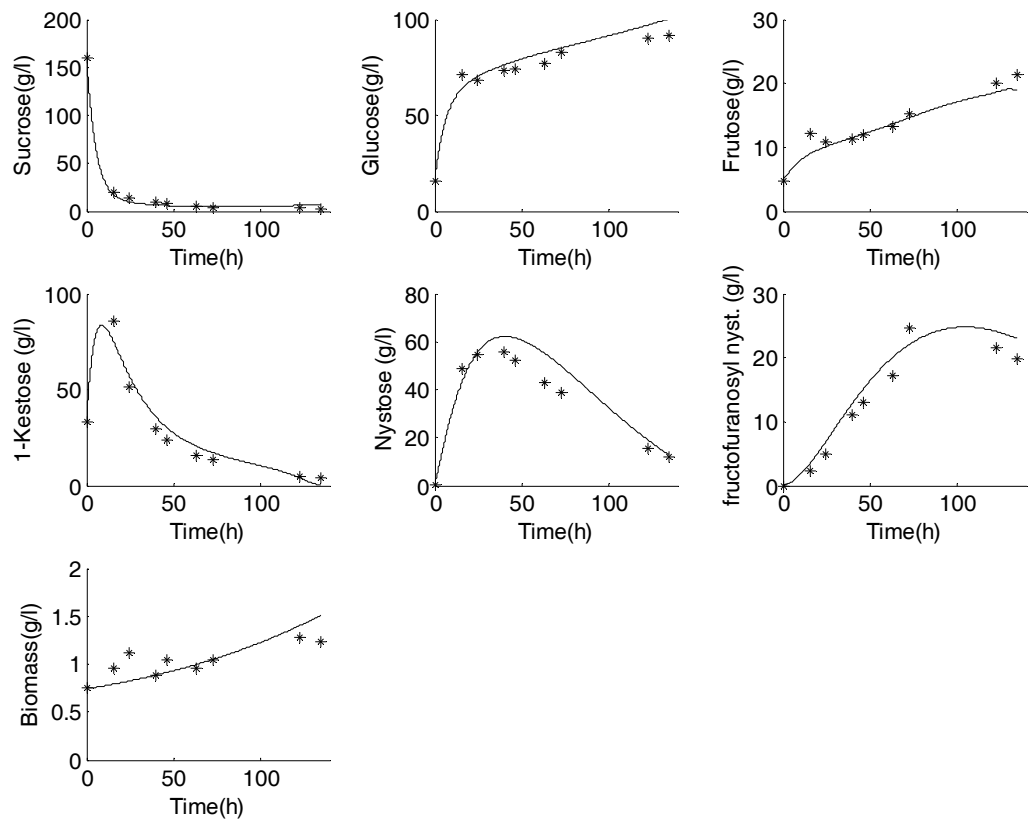

Figure 1: Comparison of Aspergillus sp. simulated and the experimental data from Ferm1. The simulation was performed with the parameters calculated from Ferm2. 
Table 1: Parameters calculated with the System Biology Toolbox for Aspergillus sp. and from literature from an Aspergillus japonicus.

\begin{tabular}{|c|c|c|c|}
\hline Parameter & $\begin{array}{l}\text { Identified value for } \\
\text { Aspergillus sp. }\end{array}$ & $\begin{array}{l}\text { Value from } \\
\text { Literature }\end{array}$ & Units \\
\hline VmhGF & $1.43 \pm 0.0924$ & -- & $g_{\text {sucrose }} 1^{-1} h^{-1}$ \\
\hline KmhGF & $111.57 \pm 8.482$ & -- & $\mathrm{g}_{\text {sucrose }} \mathrm{l}^{-1}$ \\
\hline VmtGF & $49.99 \pm 0.0858$ & 41.3 & $g_{\text {sucrose }} 1^{-1} h^{-1}$ \\
\hline Ksts & $911.16 \pm 3.627$ & 965.0 & $\mathrm{~g}_{\text {sucrose }} 1^{-1}$ \\
\hline Kmst & $70.22 \pm 0.256$ & 93.4 & $\mathrm{~g}_{\text {sucrose }} \mathrm{I}^{-1}$ \\
\hline Kgst & $24.57 \pm 0.159$ & 23.6 & $\mathrm{~g}_{\text {glicose }} \mathrm{l}^{-1}$ \\
\hline VmhGF2 & $7.58 \pm 0.0322$ & 5.8 & $\mathrm{~g}_{\text {kestose }} \mathrm{l}^{-1} \mathrm{~h}^{-1}$ \\
\hline KihGF2 & $2.72 \pm 0.375$ & 18.2 & $\mathrm{~g}_{\text {kestose }} \mathrm{l}^{-1}$ \\
\hline $\mathrm{KmhGF2}$ & $0.61 \pm 0.029$ & 428.9 & $\mathrm{~g}_{\text {kestose }} 1^{-1}$ \\
\hline VmhGF3 & $7.97 \pm 0.272$ & -- & $\mathrm{g}_{\text {nystose }} 1^{-1} \mathrm{~h}^{-1}$ \\
\hline KihGF3 & $10.52 \pm 0.374$ & -- & $\mathrm{g}_{\text {nystose }} 1^{-1}$ \\
\hline KmhGF3 & $177.41 \pm 4.922$ & -- & $\mathrm{g}_{\text {nystose }} \mathrm{l}^{-1}$ \\
\hline VmhGF4 & $7.35 \pm 0.268$ & -- & $\mathrm{g}_{\text {fructosyl }} \mathrm{l}^{-1} \mathrm{~h}^{-1}$ \\
\hline KihGF4 & $6.21 \pm 1.427$ & -- & $\mathrm{g}_{\text {fructosyl }} \mathrm{l}^{-1}$ \\
\hline KmhGF4 & $724.07 \pm 16.975$ & -- & $\mathrm{g}_{\text {fructosyl }} \mathrm{l}^{-1}$ \\
\hline VmtGF2 & $41.63 \pm 0.285$ & 30.7 & $\mathrm{~g}_{\text {kestose }} 1^{-1} \mathrm{~h}^{-1}$ \\
\hline $\mathrm{KmtGF} 2$ & $239.88 \pm 1.784$ & 349.5 & $\mathrm{~g}_{\text {kestose }} \mathrm{l}^{-1}$ \\
\hline KitGF2 & $49.96 \pm 0.216$ & 35.3 & $\mathrm{~g}_{\text {glicose }} \mathrm{l}^{-1}$ \\
\hline VmtGF3 & $11.53 \pm 0.122$ & 11.7 & gnystose $^{-1} \mathrm{l}^{-1}$ \\
\hline KmtGF3 & $333.07 \pm 2.375$ & 338.4 & $\mathrm{~g}_{\text {nystose }} 1^{-1}$ \\
\hline KitGF3 & $49.95 \pm 0.153$ & 10.3 & $\mathrm{~g}_{\text {glicose }} \mathrm{1}^{-1}$ \\
\hline $\mathrm{KmG}$ & $397.98 \pm 17.183$ & -- & $\mathrm{g}_{\text {glicose }} \mathrm{1}^{-1}$ \\
\hline$\mu \mathrm{G} \max$ & $2.89811 \mathrm{E}-05 \pm 3.94 \mathrm{e}-006$ & -- & \\
\hline $\mathrm{KmF}$ & $11.45 \pm 0.193$ & -- & $\mathrm{g}_{\text {fructose }} \mathrm{l}^{-1}$ \\
\hline$\mu$ Fmax & $0.0097 \pm 5.72 \mathrm{e}-005$ & -- & \\
\hline $\mathrm{Y}_{\mathrm{G} / \mathrm{X}}$ & $29.23 \pm 0.924$ & -- & $\mathrm{g}_{\text {glicose }} \mathrm{g}_{\text {biomass }}{ }^{-1}$ \\
\hline $\mathrm{Y}_{\mathrm{F} / \mathrm{X}}$ & $79.34 \pm 0.0617$ & -- & $\mathrm{g}_{\text {fructose }} \mathrm{g}_{\text {biomass }}{ }^{-1}$ \\
\hline
\end{tabular}

